Article

\title{
Effects of Plum Plantation Ages on Soil Organic Carbon Mineralization in the Karst Rocky Desertification Ecosystem of Southwest China
}

\author{
Hui Yang ${ }^{1,2}{ }^{-}$, Biqin Mo ${ }^{1,2}$, Mengxia Zhou ${ }^{1,2}$, Tongbin Zhu ${ }^{1,2, *}$ and Jianhua Cao ${ }^{1,2}$ \\ 1 Karst Dynamics Laboratory, Institute of Karst Geology (CAGS), Ministry of Natural Resources (MNR) and \\ Guangxi, Guilin 541004, China; yanghui-kdl@karst.ac.cn (H.Y.); mermaid_yh@126.com (B.M.); \\ mengxia.zhou95@gmail.com (M.Z.); jhcaogl@karst.ac.cn (J.C.) \\ 2 International Research Centre on Karst, Under the Auspices of United Nations Educational, Scientific and \\ Cultural Organization (UNESCO), Guilin 541004, China \\ * Correspondence: ztb@karst.ac.cn; Tel.: +86-773-583-7840; Fax: +86-773-583-7845
}

Received: 30 October 2019; Accepted: 2 December 2019; Published: 4 December 2019

\begin{abstract}
Soil organic carbon (SOC) mineralization is closely related to carbon source or sink of terrestrial ecosystem. Understanding SOC mineralization under plum plantation is essential for improving our understanding of SOC responses to land-use change in karst rocky desertification ecosystem. In this study, 2-year, 5-year, and 20-year plum plantations and adjacent abandoned land dominated by herbs were sampled, and a 90-day incubation experiment was conducted to investigate the effect of plum plantations with different ages on SOC mineralization in subtropical China. Results showed that: (1) Plum plantation significantly decreased SOC content compared with abandoned land, but there was no significant difference in SOC content among plum plantations with different ages. Oppositely, the accumulative SOC mineralization $\left(C_{t}\right)$ and potential SOC mineralization $\left(C_{0}\right)$ showed different responses to plum plantation ages. (2) The dynamics of the SOC mineralization were a good fit to a first-order kinetic model. Both $C_{0}$ and $C_{t}$ in calcareous soil of this study was several- to 10-folds lower than other soils in non-karst regions, indicating that SOC in karst regions has higher stability. (3) Correlation analysis revealed that both $C_{t}$ and $C_{0}$ was significantly correlated with soil calcium (Ca), suggesting an important role of Ca in SOC mineralization in karst rocky desertification areas. In conclusion, a Ca-rich geological background controls SOC mineralization in karst rocky desertification areas.
\end{abstract}

Keywords: calcareous soil; plum plantation ages; organic carbon mineralization; fitting parameters; organic carbon accumulation

\section{Introduction}

Due to the fragile geological and ecological conditions, rocky desertification widely occurs in the southwest karst region of China [1], which is characterized by serious soil erosion, devoid of vegetation and soil [2]. To effectively prevent rocky desertification, a series of ecological restorations have been carried out to increase the forest cover and to mitigate soil erosion by the Chinese government [3]. Consequently, various land uses, including undisturbed (e.g., grassland and shrub) and man-made (e.g., corn, woodland and fruit crop) ecosystems, have been formed in karst rocky desertification regions. These ecological restoration measures have tremendously affected the physical, chemical, and microbiological properties in soils [4]. Plum plantation is one of the local sustainable development models of characteristic agriculture in karst rocky desertification areas, which can not only effectively restore the ecological environment, but also significantly increase farmers' income in local. In recent 
years, the planting area of plum trees has been increasing continuously in the process of controlling rocky desertification [5].

Dynamic change of soil organic carbon (SOC) is of great significance to global $\mathrm{C}$ cycle and current climate change. The quantity and intensity of carbon dioxide $\left(\mathrm{CO}_{2} ;\right.$ an important greenhouse gas) released by SOC mineralization through microbial decomposition can reflect the quality of soil and evaluate soil carbon emissions into the atmosphere [6,7]. In addition, SOC mineralization is closely related to the maintenance of soil nutrients and the formation of $\mathrm{CO}_{2}$ [8]. The $\mathrm{CO}_{2}$ emission rate and its dynamic change process are also important indicators reflecting the change of soil quality. Furthermore, SOC concentration at a particular time is controlled by the balance between $\mathrm{C}$ input from litter and C output from SOC mineralization [9]. Investigating the SOC mineralization process is the most effective methods to evaluate $C$ loss or stability [10].

Vegetation type influences the rate of accumulation and mineralization of organic matter in forest soil [11]. Some research proved that $C$ loss from soil respiration depends on stand age. It is low in young, high in intermediate, and low again in old stands [12,13]. Plum is one of the principal tree species in the rocky desertification restoration area in the National Sustainable Development Experiment and Demonstration Zone in Gongcheng county. However, there is less study about SOC storage and SOC mineralization in plum forests in rocky desertification restoration areas. In particular, it is not clear whether plum plantation age is the key factor controlling SOC stability and how other factors influence SOC decomposition dynamics. In addition, calcareous soil developed on carbonate rock is characterized by high $\mathrm{pH}$ and Ca materials in a karst region [1], which may lead to the obvious differences in SOC mineralization compared to other soil types. The lack of knowledge regarding SOC mineralization under plum plantation during karst rocky desertification restoration limits the ability to predict how this ecosystem will respond to climate change. We hypothesized that both the karst geological background, especially soil $\mathrm{pH}$ and Ca concentrations, and plantation ages may play an important role in controlling SOC mineralization.

Therefore, we measured the distribution and mineralization of organic $C$ in soils collected from plum fields with different plantation ages ( 2 year, 5 year, and 20 year) and adjacent abandoned land in the karst rocky desertification region of subtropical China. The main objectives of this study were to (1) estimate SOC content, mineralization, and soil nutrients under plum plantations with different stand ages; (2) evaluate the relative importance of soil properties affecting SOC content and mineralization; (3) potentially assess mineralization and decomposition rates of SOC.

\section{Materials and Methods}

\subsection{Study Area}

The study site was located in the National Sustainable Development Experiment and Demonstration Zone and also a key area of national rocky desertification control in Gongcheng county, Guilin, Guangxi Zhuang Autonomous Region $\left(110^{\circ} 47^{\prime} 4^{\prime \prime}\right.$ E, $\left.24^{\circ} 54^{\prime} 35^{\prime \prime} \mathrm{N}\right)$ (Figure 1), which is a subtropical monsoon climate, with an annual average temperature of $19.7^{\circ} \mathrm{C}$ and an annual average precipitation of $1438 \mathrm{~mm}$.

The study area is a hilly and middle-low mountain landform. Its parent material is carboniferous limestone. Karst soil is sparse and drought-prone. Because of long-term human activities, natural vegetation is destroyed and large areas of steep slopes are reclaimed, resulting in surface rock bareness, coupled with thin soil layer, shallow bedrock exposure, storm erosion, and a large number of rocks gradually exposed after soil erosion. Severe rocky desertification occurs (Figure S1). 


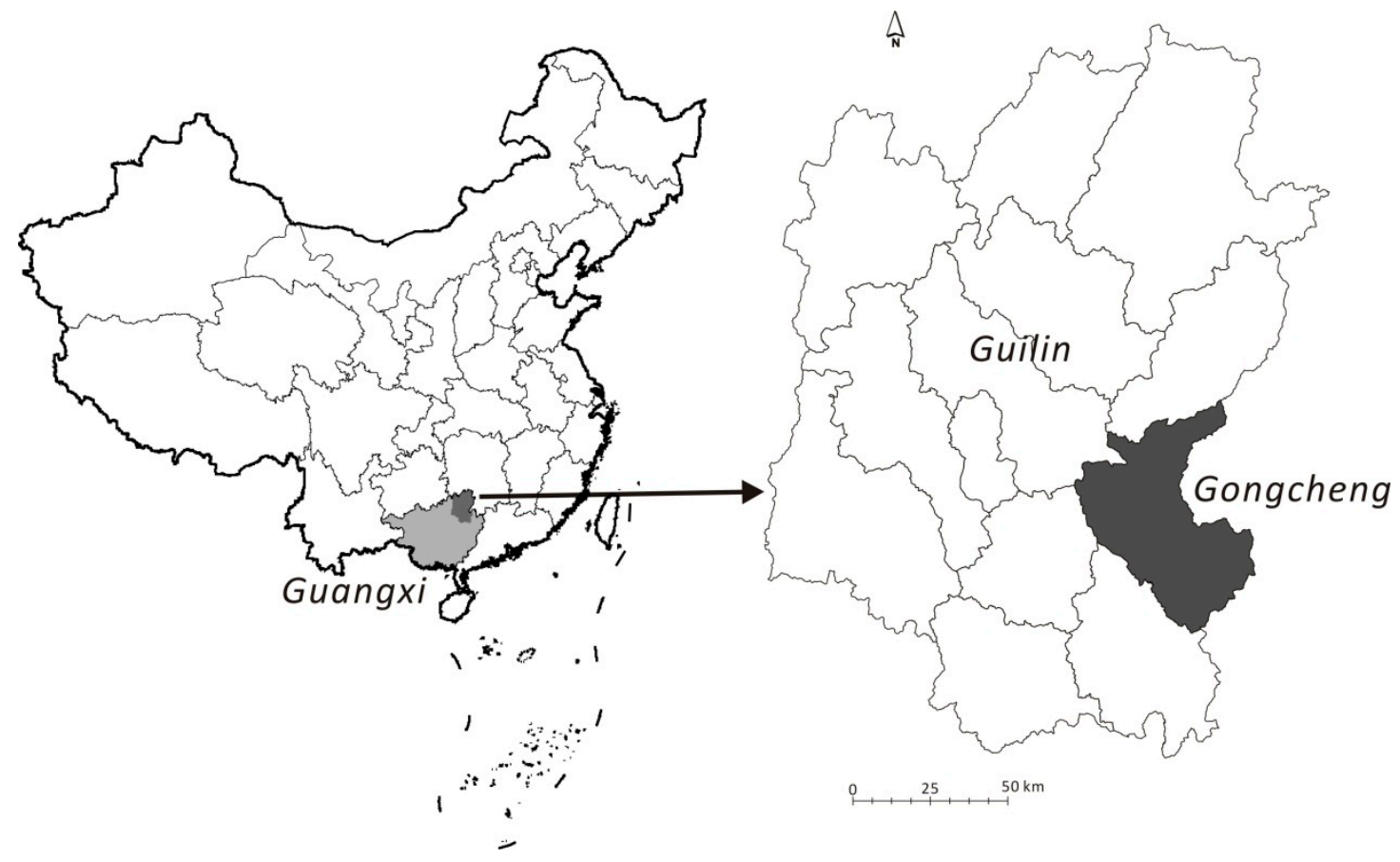

Figure 1. The location of the study area.

\subsection{Soil Sampling and Preparation}

Soil samples were collected from three plum fields with 2-year, 5-year, and 20-year plantation ages, and abandoned land was used as control. The understory of the plum plantation was dominated by the meda villosa (Poir.) A. Camus and Digitaria sanguinalis (Linn.) Scop. The dominated plants of the abandoned land were herbs, dominated by Miscanthus with a small amount of Conyza canadensis (Linn.) Cronq. Fertilizer was applied four times each year, including three times of chemical fertilizer and one time of organic fertilizer. The chemical fertilizer was compound fertilizer (including N 18\%, $\mathrm{P}_{2} \mathrm{O}_{5} 18 \%, \mathrm{~K}_{2} \mathrm{O} 18 \%$ ). The organic fertilizer was cattle manure (including C $413.8 \mathrm{~g} \mathrm{~kg}^{-1}, \mathrm{~N}_{2.7} \mathrm{~g} \mathrm{~kg}^{-1}$, $\mathrm{P}_{2} \mathrm{O}_{5} 1.3 \mathrm{~g} \mathrm{~kg}^{-1}, \mathrm{~K}_{2} \mathrm{O} 6.0 \mathrm{~g} \mathrm{~kg}^{-1}$ ). Under each plum tree, an average of $2 \mathrm{~kg}$ of chemical fertilizer and $20 \mathrm{~kg}$ of organic fertilizer were applied each year. The application rate of $\mathrm{N}_{2} \mathrm{P}_{2} \mathrm{O}_{5}$, and $\mathrm{K}_{2} \mathrm{O}$ reached to approximately 250,100 , and $240 \mathrm{~kg} \mathrm{ha}^{-1}$ year $^{-1}$, respectively.

In November 2015, three representative sites were sampled for plum plantations with different ages and abandoned land as spatial replications, resulting in 12 soil samples. In each site, three $20 \mathrm{~m}$ $\times 20 \mathrm{~m}$ plots with similar architecture and growth of plum trees, separated at least $40 \mathrm{~m}$ from each other, were randomly selected. Soils of the top $0-10 \mathrm{~cm}$ were collected from five quadrats $(1 \mathrm{~m} \times 1$ $\mathrm{m}$ ) in each plot; one on each corner and one in the center were mixed to form a composite sample. After removing animal and plant debris and stones, the collected samples were air-dried at room temperature. The composite samples were divided into two parts. One part of the collected sample was passed through a 2-mm sieve to carry out SOC mineralization experiment, and the other part was grinded and passed through a $0.25-\mathrm{mm}$ sieve and homogenized for soil physical and chemical property determination, including $\mathrm{pH}$, SOC, total nitrogen (TN), total phosphorus (TP), total potassium (TK), and calcium $(\mathrm{Ca})$.

\subsection{Experiment Design}

A laboratory incubation experiment was carried out to determine SOC mineralization. Soil samples were incubated with a constant temperature regime at $20^{\circ} \mathrm{C}$, which was close to the annual mean temperature $\left(19.7^{\circ} \mathrm{C}\right)$ in the sampled area. The incubation temperatures were controlled by digital biochemical incubators (SPX-70B, Hangzhou Julai Instrument Co., Ltd., Hangzhou, China). 
Each soil sample (100 g dry), including three repeats, was placed in a $1000 \mathrm{~mL}$ incubation jar (Figure S2). The soil moisture content was adjusted to $60 \%$ of field capacity prior to incubation. All samples were pre-incubated at $20^{\circ} \mathrm{C}$ for 7 days to minimize the burst of respiration due to wetting the dry soils [10]. Then, a $50 \mathrm{~mL}$ beaker containing $10 \mathrm{~mL}$ of $0.1 \mathrm{~mol} / \mathrm{L} \mathrm{NaOH}$ solution was placed at the bottom of the incubation jar, sealed and capped, and incubated in a $20^{\circ} \mathrm{C}$ thermostat in darkness. Three blank controls (no soil addition) were arranged at the same time in order to eliminate the influence of $\mathrm{CO}_{2}$ in the air when $\mathrm{NaOH}$ solution was replaced every time. A total of 39 samples, including 12 soil samples with 3 incubation replicates and 3 blank controls, were used for the incubation experiment. Deionized water was added to the soil twice a week to keep the loss of soil water within $2 \%$ [14]. The $50 \mathrm{~mL}$ beaker containing $10 \mathrm{~mL}$ of $0.1 \mathrm{~mol} / \mathrm{L} \mathrm{NaOH}$ solution was replaced at days 2, 5, 8, 14, 20, 26, $32,38,44,62,74$, and 90 . The amount of $\mathrm{CO}_{2}$ released during incubation can be calculated by titrating residual $\mathrm{NaOH}$ with $0.1 \mathrm{~mol} / \mathrm{L} \mathrm{HCl}$ solution.

\subsection{Methods}

Soil $\mathrm{pH}$ was determined at a 1:2.5 (w/v) soil/water ratio by a digital millivolt $\mathrm{pH}$ Meter-2 (DMP-2 $\mathrm{mV} / \mathrm{pH}$ ) detector (Quark Ltd., Nanjing, China); SOC was determined using the $\mathrm{K}_{2} \mathrm{Cr}_{2} \mathrm{O}_{7}-\mathrm{H}_{2} \mathrm{SO}_{4}$ volumetric dilution heating method; total nitrogen was determined using the Kjeldahl procedure [15]; total potassium (TK) concentration was determined with the $\mathrm{HF}-\mathrm{HClO}_{4}$ flame photometric method; and total phosphorus (TP) was measured using $\mathrm{HClO}_{4}-\mathrm{H}_{2} \mathrm{SO}_{4}$ digestion followed by an Mo-Sb colorimetric assay [1]; soil calcium (Ca) was extracted by $\mathrm{HNO}_{3}-\mathrm{HF}-\mathrm{HClO}_{4}$ and analyzed by inductively coupled plasma-atomic emission spectrometry (ICP-AES). Three replicates were performed for each soil sample.

The mineralization of SOC was calculated by the following Equation (1).

$$
\mathrm{C}_{\mathrm{m}}=\mathrm{C}_{\mathrm{HCl}} \times\left(\mathrm{V}_{0}-\mathrm{V}_{1}\right) \times 22 / 0.1
$$

where $\mathrm{C}_{\mathrm{m}}$ was the amount of $\mathrm{CO}_{2}$ release $\left(\mathrm{mg} \mathrm{CO}_{2} / \mathrm{kg}\right.$ soil); $\mathrm{C}_{\mathrm{HCl}}$ was the concentration of hydrochloric acid (mol/l); $\mathrm{V}_{0}$ was the volume of hydrochloric acid consumed in blank titration (ml); $\mathrm{V}_{1}$ was the volume of hydrochloric acid consumed in titration of samples (ml); 22 was half of the Molar mass of $\mathrm{CO}_{2}(\mathrm{~mol} / \mathrm{kg}) ; 0.1$ was soil weight $(\mathrm{kg})$.

\subsection{Data Analysis}

The data was fitted in an exponential model using the data analysis and graphing software (Origin ver. 7.5; Origin Lab Corp., Northampton, MA, USA) to obtain kinetics of SOC mineralization (Equation (2)) [16].

$$
C_{t}=C_{0}\left(1-\mathrm{e}^{-k t}\right)
$$

where $C_{t}$ was the cumulative mineralization of SOC after $t$ days; $C_{0}$ was amount of potential mineralizable SOC $(\mathrm{mg} / \mathrm{kg}) ; k$ for constant of mineralization rate of SOC (/day).

The half-turnover period was calculated by Equation (3).

$$
\mathrm{T}_{1 / 2}=1 \mathrm{n} 2 / \mathrm{k}
$$

where $T_{1 / 2}$ was half the turnover period (day).

The obtained data were statistically analyzed using the analysis Statistical Package Social Science (SPSS ver. 20.0; IBM Corp., Armonk, NY, USA) to compare the analysis of variance. Tukey's honestly significant difference (HSD) was then calculated for indicating the significant differences in soil properties and SOC mineralization $(p<0.05)$. Graphs were plotted using the Origin 7.5 program. The correlations between the SOC mineralization and the soil chemical properties were analyzed by the Pearson correlation test. 


\section{Results}

\subsection{Soil Chemical Properties as Affectted by Plantation Age}

Compared to abandoned land, plum plantation significantly decreased $\mathrm{pH}$ and the contents of SOC and TN $(p<0.05)$ (Table 1$)$, but there was no significant difference among plum plantations with different ages $(p>0.05)$. Although $\mathrm{C} / \mathrm{N}$ ratios in soils under plum plantation were lower than that under abandoned land, the significant difference was not found between abandoned land and plum plantations. There was no significant difference in TP contents among abandoned land and three plum plantations $(p>0.05)$. The highest TK contents were found in soils under 5-year plum plantation and abandoned land, which were significantly higher than 2-year and 20-year plum plantations. Plum plantation significantly decreased Ca contents compared with abandoned land $(p<0.05)$, with the lowest in soil under 5-year plum plantation.

Table 1. Soil properties under plum plantations with different ages.

\begin{tabular}{cccccccc}
\hline & pH & SOC $(\mathrm{g} / \mathbf{k g})$ & TN $(\mathrm{g} / \mathbf{k g})$ & C/N & TP $(\mathrm{g} / \mathbf{k g})$ & TK $(\mathrm{g} / \mathbf{k g})$ & Ca $(\%)$ \\
\hline CK & $6.60 \pm 0.10^{\mathrm{a}}$ & $22.38 \pm 0.53^{\mathrm{a}}$ & $1.01 \pm 0.04^{\mathrm{a}}$ & $25.97 \pm 1.62^{\mathrm{a}}$ & $0.49 \pm 0.08^{\mathrm{a}}$ & $18.07 \pm 0.05^{\mathrm{a}}$ & $0.97 \pm 0.13^{\mathrm{a}}$ \\
2 year & $5.31 \pm 0.32^{\mathrm{b}}$ & $11.87 \pm 3.18^{\mathrm{b}}$ & $0.61 \pm 0.18^{\mathrm{b}}$ & $22.83 \pm 2.82^{\mathrm{a}}$ & $0.55 \pm 0.25^{\mathrm{a}}$ & $14.56 \pm 0.55^{\mathrm{b}}$ & $0.54 \pm 0.23^{\mathrm{b}}$ \\
5 year & $5.91 \pm 0.51^{\mathrm{c}}$ & $10.17 \pm 3.28^{\mathrm{b}}$ & $0.74 \pm 0.20^{\mathrm{ab}}$ & $17.96 \pm 8.61^{\mathrm{a}}$ & $0.44 \pm 0.21^{\mathrm{a}}$ & $19.47 \pm 1.68^{\mathrm{a}}$ & $0.27 \pm 0.10^{\mathrm{c}}$ \\
20 year & $5.17 \pm 0.28^{\mathrm{b}}$ & $11.70 \pm 5.27^{\mathrm{b}}$ & $0.66 \pm 0.27^{\mathrm{b}}$ & $21.34 \pm 6.50^{\mathrm{a}}$ & $0.63 \pm 0.31^{\mathrm{a}}$ & $15.06 \pm 1.25^{\mathrm{b}}$ & $0.40 \pm 0.16^{\mathrm{bc}}$ \\
\hline
\end{tabular}

Note: CK represents abandoned land; 2 year represents plum forest plantation for 2 years; 5 year represents plum forest plantation for 5 years; 20 year represents plum forest plantation for 20 years. SOC represents soil organic carbon; TN represents total nitrogen; $\mathrm{C} / \mathrm{N}$ represents the molar ratio of soil organic carbon (SOC)/TN; TP represents total phosphorus; TK represents total potassium; Ca represents calcium. Identical letters indicate no significant differences in the average values among soils under different plantation ages at the 0.05 level.

\subsection{Mineralization Rate of Soil Organic C under Plum Plantations with Different Ages}

Soil organic carbon mineralization rate decreased with incubation time (Figure 2), and accorded with logarithmic function $y=\mathrm{a}+\mathrm{b} \ln (x)$ (Table 2), indicating that SOC mineralization rate would change $b \%$ absolute value when incubation time changed by $1 \%$ unit.

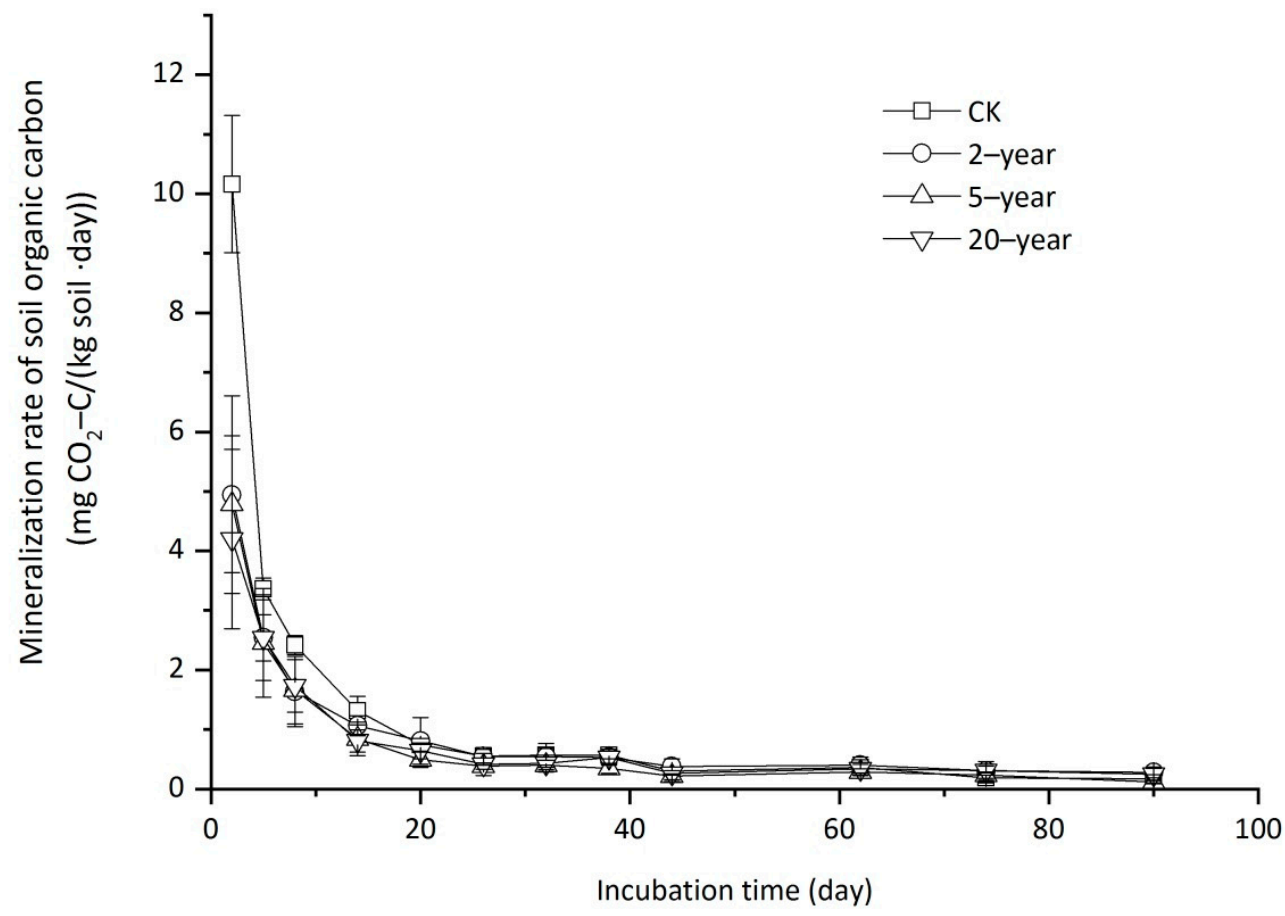

Figure 2. Daily mineralization rate of soil organic carbon. 
Table 2. Regression equation of SOC mineralization rate relative to plum plantation age.

\begin{tabular}{ccc}
\hline Treatment & Regression Equation & $\boldsymbol{R}^{\mathbf{2}}$ \\
\hline CK & $y=8.221-2.101 \ln (x)$ & $0.734^{* *}$ \\
2 year & $y=4.499-1.078 \ln (x)$ & $0.835^{* *}$ \\
5 year & $y=4.736-1.085 \ln (x)$ & $0.831^{* *}$ \\
20 year & $y=4.040-0.971 \ln (x)$ & $0.853^{* *}$ \\
\hline
\end{tabular}

Note: $y$ represents $\mathrm{CO}_{2}$ production rate; $x$ represents incubation day; ${ }^{* *}$ means significant correlation at 0.01 level.

Based on the decline rate of SOC mineralization (Figure 2), it can be divided into three stages. The first stage (2-14 days) was the early stage of the incubation. The rate of $\mathrm{CO}_{2}$ production decreased rapidly from the peak ( 2 days) and changed greatly. There was no significant difference in the mineralization rate of SOC among three planting ages, but it was significantly lower than CK. The second stage (14-62 days) was the medium stage of the incubation, and the rate of $\mathrm{CO}_{2}$ production declined from a slow stage to a stable stage. The SOC mineralization rate of CK was higher than that in the three planting ages. At the last stage (62-90 days), the SOC mineralization rate of CK began to be lower than that of soils under plum plantations with different ages, and the difference was significant.

\subsection{Cumulative Mineralization of Soil Organic Carbon Under Plum Plantations with Different Ages}

Carbon mineralization showed a curvilinear relationship with time over the incubation period (starting from 0 to day 90) (Figure 3). Across different plantation ages, cumulative $\mathrm{CO}_{2}-\mathrm{C}$ emission varied from $2.29 \mathrm{mg} \mathrm{CO}-\mathrm{C} / \mathrm{kg}$ soil (day 2) to $61.17 \mathrm{mg} \mathrm{CO}-\mathrm{C} / \mathrm{kg}$ soil (day 90 ).

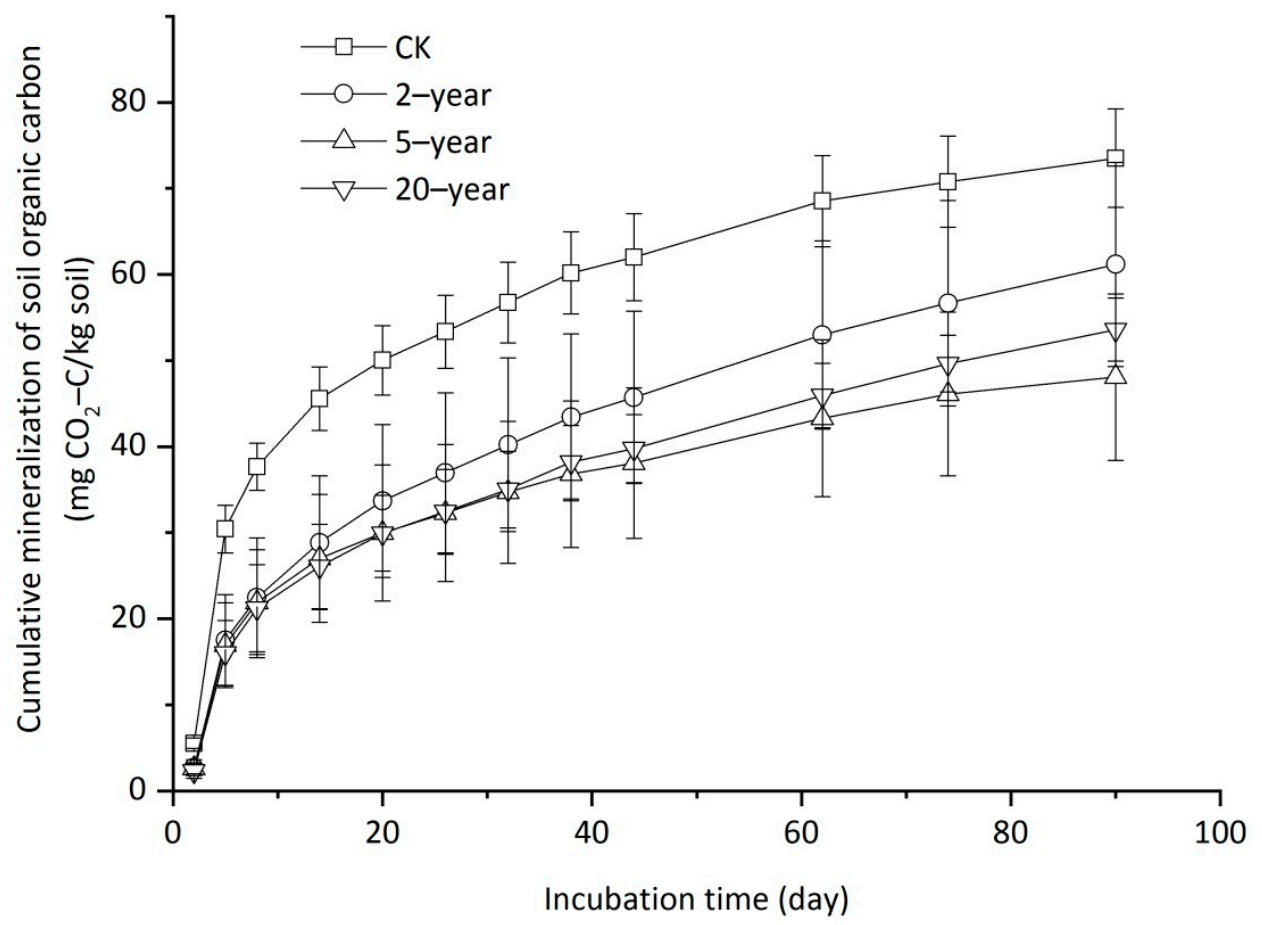

Figure 3. Cumulative mineralization of SOC relative to plum plantation age.

The cumulative release of $\mathrm{CO}_{2}$ increased with incubation time, but the cumulative release intensity gradually slowed down. During the whole incubation, the cumulative release of $\mathrm{CO}_{2}$ was higher in $\mathrm{CK}$ than that in plum plantations with different ages. The cumulative release of $\mathrm{CO}_{2}$ was ranked as 2-year, 20-year, and 5-year plantations. 


\subsection{Parameters of Soil Organic Carbon Mineralization Kinetic Equations Under Plum Plantations with Different Ages}

The first-order kinetic equation was used to fit the cumulative mineralization of SOC under plum plantations with different ages, and the fitting results were good $\left(R^{2}>0.90\right)$. The potential mineralization of SOC $\left(\mathrm{C}_{0}\right)$ and constant for SOC mineralization rate $(k)$ estimated from the first-order kinetic equation are shown in Table 3. The values of $C_{0}$ ranged from 44.13 (5-year) to $67.10 \mathrm{mg} / \mathrm{kg}(\mathrm{CK})$, and it was significant higher in $\mathrm{CK}$ than that in plum plantations $(p<0.05)$. The $\mathrm{CO}_{2}-\mathrm{C}$ release from mineralization of soil potential organic $C$, i.e., the turnover rate $(k)$ of bioactive organic carbon pool, ranged from 0.043 (2-year) to 0.079 day $^{-1}(\mathrm{CK})$, and the half-turnover period was $8.80(\mathrm{CK})-16.1$ day (2-year) (Table 3). The values of $k$ for different plum plantation ages showed the same trend with $\mathrm{C}_{0}$. With increasing plum plantation age, soil potential mineralized $C$ pool decreased, but soil potential mineralized C pool increased slightly after 20-year plum plantation, although the difference was not significant between 5-year and 20-year plum plantations $(p>0.05)$.

Table 3. Cumulative mineralization of SOC after the 90 days of incubation and parameters of its kinetic equations.

\begin{tabular}{ccccccc}
\hline Treatment & $C_{\boldsymbol{t}}(\mathbf{m g} / \mathbf{k g})$ & $\boldsymbol{C}_{\mathbf{0}}(\mathbf{m g} / \mathbf{k g})$ & $k(\mathbf{d})$ & $\mathbf{T}_{\mathbf{1} / \mathbf{2}}(\mathbf{d})$ & $\mathbf{C}_{\mathbf{0}} / \mathbf{S O C}(\mathbf{\%})$ & $\boldsymbol{R}^{\mathbf{2}}$ \\
\hline CK & $73.52 \pm 8.43^{\mathrm{a}}$ & $67.10 \pm 7.56^{\mathrm{a}}$ & $0.079 \pm 0.003^{\mathrm{a}}$ & 8.80 & 0.30 & 0.93 \\
2-year & $61.17 \pm 5.56^{\mathrm{b}}$ & $57.92 \pm 1.33^{\mathrm{b}}$ & $0.043 \pm 0.001^{\mathrm{b}}$ & 16.1 & 0.49 & 0.96 \\
5-year & $48.09 \pm 3.27^{\mathrm{c}}$ & $44.13 \pm 5.71^{\mathrm{c}}$ & $0.060 \pm 0.001^{\mathrm{c}}$ & 11.6 & 0.43 & 0.93 \\
20-year & $53.60 \pm 4.11^{\mathrm{c}}$ & $49.85 \pm 2.55^{\mathrm{c}}$ & $0.046 \pm 0.002^{\mathrm{b}}$ & 15.1 & 0.43 & 0.94 \\
\hline
\end{tabular}

Note: $C_{t}$ represents cumulative mineralization of SOC; $C_{0}$ represents amount of potential mineralizable SOC; $k$ represents constant of mineralization rate of $S O C ; \mathrm{T}_{1 / 2}$ represents half-turnover period; $\mathrm{C}_{0} / \mathrm{SOC}$ represents ratio of potential mineralizable organic carbon to total organic carbon in soil. Values followed by different letters in the same column mean significance at 0.05 level.

\subsection{SOC Mineralization as Affected by Chemical Properties}

Many environmental factors might influence the mineralization of SOC [17]. Soil organic carbon content was positively correlated with $\mathrm{C}_{\mathrm{t}}$ and $\mathrm{C}_{0}$. Therefore, the difference of SOC mineralization in plum plantations with different ages was mainly due to the difference in SOC content. The proportion of active organic $\mathrm{C}$ varies with the content of SOC. Among the many factors, the Ca content and $\mathrm{C} / \mathrm{N}$ ratio significantly affect SOC mineralization (Table 4). The mineralization rate of SOC was the highest in the abandoned land with the highest $\mathrm{Ca}$ content and $\mathrm{C} / \mathrm{N}$ ratio.

Table 4. Correlations between the $\mathrm{C}$ parameters and soil property factors.

\begin{tabular}{cccccccc}
\hline & $\mathbf{p H}$ & SOC & TN & C/N & TP & TK & Ca \\
\hline$C_{\mathrm{t}}$ & 0.593 & $0.923^{* *}$ & 0.690 & $0.974^{* *}$ & -0.035 & -0.079 & $0.959 * *$ \\
$\mathrm{C}_{0}$ & 0.524 & $0.883^{*}$ & 0.621 & $0.981^{* *}$ & 0.014 & -0.159 & $0.931^{* *}$ \\
$k$ & $0.986^{* *}$ & $0.823^{*}$ & $0.983^{* *}$ & 0.423 & -0.627 & 0.741 & 0.733 \\
\hline \multicolumn{7}{r}{ * Significant correlation $(p<0.05){ }^{* *}$ Extremely significant correlation $(p<0.01)}$.
\end{tabular}

\section{Discussion}

\subsection{Effects of Plantation Ages on Soil Chemical Properties}

Plum plantation significantly reduced SOC content by about $50 \%$ compared with abandoned land, which may be attributed to the changes in agricultural managements (e.g., the clear-cut of forest, tillage and mineral $\mathrm{N}$ fertilizer). Except for the direct reduction in litter input to soil, weed control, tillage, and mineral $\mathrm{N}$ fertilizer can also stimulate the decomposition of SOC, thereby lowing SOC content. Despite applying large organic fertilizer during plum plantation, it may not counterbalance the negative effect on SOC consumption through litter reduction and agricultural managements. However, 
SOC contents did not exhibit the obvious differences among plum plantations with different ages, suggesting that SOC pool is maintained at the relatively stable level once grassland is converted to plum, irrespective of plum plantation years.

The $\mathrm{C} / \mathrm{N}$ value in the studied soils was relatively stable, and no significant difference was found among plum plantations with different ages. This was in agreement with the previous result that the $\mathrm{C} / \mathrm{N}$ ratio was relatively stable and was insignificantly affected by climate, although $\mathrm{C}$ and $\mathrm{N}$ concentrations had great spatial variability [1]. Compared with abandoned land, TP content in soil under plum plantation did not significantly change, which was consistent with a previous study that TP was mainly derived from the weathering release of soil minerals, rather than from the short-term biological cycle in karst rocky desertification areas [1]. Oppositely, potassium sources in soil are mainly derived from potassium minerals and fertilization. With the increase of plum plantation ages, Ca content in soil decreased obviously, which may be because plum trees absorb a lot of Ca as one of the nutrient elements in the process of growth.

\subsection{SOC Mineralization and Affecting Factors}

In this study, $\mathrm{CO}_{2}$ production rate is faster in the initial stage of incubation, possibly owing to the priming effect [18]. After pre-incubation, a large number of active organic substances such as sugars and proteins can be effectively decomposed by microorganisms in the initial stage of mineralization [8]. Greater SOC mineralization in abandoned land than plum plantations was often attributed to greater total SOC [19] or greater labile SOC, e.g., dissolved organic carbon (DOC) and microbial biomass $\mathrm{C}(\mathrm{MBC})$, which could stimulate the abundance and activity of microorganisms, and subsequently accelerate SOC mineralization $[20,21]$. With the prolongation of incubation time, the mineralization rate of SOC gradually decreased with decreasing decomposable organic matter. At the later stage of incubation, the organic matter in soil was mainly composed by cellulose and lignin [18], which were difficult to decompose and could not be utilized by microorganisms, resulting in the decline of the mineralization rate of organic carbon. The $\mathrm{CO}_{2}$ efflux rate in this study showed a similar trend with many research results $[8,18,22]$. In addition, the relationship between SOC mineralization rate and incubation time was logarithmic function, which was consistent with previous research results $[8,23,24]$.

The cumulative mineralization and mineralization rate of SOC under plum plantations with different ages decreased compared to abandoned land. High $\mathrm{CO}_{2}$ emissions probably indicate high biological activities in soil [25] and this might take place through microbial exhalation [26], as well as the emissions of $\mathrm{CO}_{2}$ during organic matter decomposition [27]. Thus, it is no wonder to find out that the efflux rate of $\mathrm{CO}_{2}$ from the plantation soils was lower than that in abandoned land. The long-term application of chemical fertilizer during plum plantation is not conducive to the formation of soil aggregates. This may exacerbate the microbial growth environment, resulting in the decrease of soil microbial biomass [28]. It may also be that $\mathrm{N}$ in fertilizer combines with lignin in soil to form more stable organic compounds [29], which then inhibits the mineralization of SOC. The mechanism of soil characteristics affecting microbial species and activities in plum forests of different ages in karst mountainous areas remains to be further studied.

\subsection{Carbon Pool Stability and Factors that Potentially Affect SOC Decomposition}

Both cumulative $\mathrm{CO}_{2}-\mathrm{C}$ emission and potential mineralizable SOC in calcareous soil of this study was several- to 10 -folds lower than that in other soils $[8,13,17]$, similar to the results in soils of karst regions [30], indicating that SOC in karst regions has higher stability. Both $\mathrm{Ca}$ and $\mathrm{C} / \mathrm{N}$ were important factors affecting SOC mineralization in this study. Soil C/N affects the abundance, activity, and community composition of microorganisms [31]. Calcium is the necessary metabolic component of microbial growth, and fungal and bacterial heterotrophs may access and accumulate root Ca to form oxalates, which can be used to maintain microbial metabolism under unfavorable soil conditions. Therefore, it has an important influence on the decomposition of SOC. 


\section{Conclusions}

The amount of SOC mineralization is governed by the net $C$ content in soil. Results of this research showed that mineralization of SOC occurred, but was somewhat several- to 10-folds lower in karst soils, indicating that SOC in karst regions has higher stability. The higher SOC and the consequent higher release of $\mathrm{CO}_{2}$ in this study may indicate a reversible equilibrated process between decomposition of soil organic matter and buildup of more stable organic components at the same time. The mineralization of SOC under plum plantation is significantly correlated with soil Ca, suggesting an important role of $\mathrm{Ca}$ in SOC mineralization in rocky desertification areas. Furthermore, it was also found that agricultural management, e.g., fertilization and weed control under plum forests, may play an important role in SOC mineralization.

Supplementary Materials: The following are available online at http://www.mdpi.com/1999-4907/10/12/1107/s1: Figure S1. Rocky desertification in the study area; Figure S2. The sketch of the incubation device.

Author Contributions: Conceptualization, J.C.; writing—original draft preparation, H.Y.; investigation, B.M. and M.Z.; writing-review and editing, T.Z.

Funding: This study was supported by the National Key Research and Development Program of China (No.2016YFC0502501; No.2017YFC0406104), the Guangxi National Science Foundation (2017GXNSFAA198153) and the Guangxi Scientific Research and Technology Development Project Guikeneng 1598023-1, the CAGS research Fund (YWF201715, 201724), and the program of Hainan Association for Science and Technology Plans to Youth R \& D Innovation (QCXM201713).

Acknowledgments: Special thanks to the anonymous referees for their valuable comments and suggestions. The authors also thank Chunlai Zhang and Bing Bai for their help with field work.

Conflicts of Interest: The authors declare no conflicts of interest.

\section{References}

1. Yang, H.; Zhang, P.; Zhu, T.; Li, Q.; Cao, J. The characteristics of soil C, N, and P stoichiometric ratios as affected by geological background in a karst graben area, Southwest China. Forests 2019, 10, 601. [CrossRef]

2. Yuan, D.X. Rock desertification in the subtropical Karst of South China. Z. Geomorphol. 1997, 108, 81-90.

3. Li, W.H. Degradation and restoration of forest ecosystems in China. For. Ecol. Manag. 2004, 201, 33-41.

4. Singh, K.; Singh, B.; Singh, R.R. Changes in physico-chemical, microbial and enzymatic activities during restoration of degraded sodic land: Ecological suitability of mixed forest over monoculture plantation. Catena 2012, 96, 57-67. [CrossRef]

5. Guangxi Daily. Available online: http://www.forestry.gov.cn/main/138/20190613/075621420562132.html (accessed on 13 June 2019).

6. Li, S.J.; Qiu, L.P.; Zhang, X.C. Mineralization of soil organic carbon and its relations with soil physical and chemical properties on the Loess Plateau. Acta Ecol. Sin. 2010, 30, 1217-1226. (In Chinese)

7. Smith, P. Carbon sequestration in croplands: The potential in Europe and the global context. Eur. J. Agron. 2004, 20, 229-236. [CrossRef]

8. Guo, Z.; Wang, X.L.; Duan, J.J.; Jiao, K.Q.; Sun, S.S.; Duan, Y.H.; Zhang, Y.R.; Li, Y.; Jiang, T.M. Long-term fertilization and mineralization of soil organic carbon in paddy soil from yellow earth. Acta Pedol. Sin. 2018, 55, 225-235. (In Chinese)

9. Vesterdal, L.; Elberling, B.; Christiansen, J.R.; Callesen, I.; Schmidt, I.K. Soil respiration and rates of soil carbon turnover differ among six common European tree species. For. Ecol. Manag. 2012, 264, 185-196. [CrossRef]

10. Huang, J.; Lin, T.C.; Xiong, D.; Yang, Z.; Liu, X.; Chen, G.; Xie, J.; Li, Y.; Yang, Y. Organic carbon mineralization in soils of a natural forest and a forest plantation of southeastern China. Geoderma 2019, 344, 119-126. [CrossRef]

11. Malý, S.; Fiala, P.; Reininger, D.; Obdržálková, E. The relationships among microbial parameters and the rate of organic matter mineralization in forest soils, as influenced by forest type. Pedobiologia 2014, 57, 235-244. [CrossRef]

12. Pregitzer, K.S.; Euskirchen, E.S. Carbon cycling and storage in world forests: Biome patterns related to forest age. Glob. Chang. Biol. 2004, 10, 2052-2077. [CrossRef] 
13. Liu, L.; Wang, H.; Dai, W. Characteristics of soil organic carbon mineralization and influence factor analysis of natural Larix olgensis forest at different ages. J. For. Res. 2019, 30, 1495-1506. [CrossRef]

14. Chen, X.; Tang, J.; Jiang, L.; Li, B.; Chen, J.; Fang, C. Evaluating the impacts of incubation procedures on estimated Q10 values of soil respiration. Soil Biol. Biochem. 2010, 42, 2282-2288. [CrossRef]

15. Gao, Y.; He, N.; Yu, G.; Chen, W.; Wang, Q. Long-term effects of different land use types on C, N, and P stoichiometry and storage in subtropical ecosystems: A case study in China. Ecol. Eng. 2014, 67, 171-181. [CrossRef]

16. Stanford, G.; Smith, S.J. Nitrogen mineralization potentials of soils 1. Soil Sci. Soc. Am. J. 1972, 36, 465-472. [CrossRef]

17. Ahmed, A.A.; Mohamed, H.H.A.; Tamer, M.S.A.; Walid, E.B.; Samira, E.M. Mineralization of organic carbon and nitrogen in semi-arid soils under organic and inorganic fertilization. Environ. Technol. Innov. 2018, 9 , 243-253.

18. Munda, S.; Bhaduri, D.; Mohanty, S.; Chatterjee, D.; Tripathi, R.; Shahid, M.; Kumar, U.; Bhattacharyya, P.; Kumar, A.; Adak, T.; et al. Dynamics of soil organic carbon mineralization and C fractions in paddy soil on application of rice husk biochar. Biomass Bioenergy 2018, 115, 1-9. [CrossRef]

19. Yang, K.; He, R.; Yang, W.; Li, Z.; Zhuang, L.; Wu, F.; Tan, B.; Liu, Y.; Zhang, L.; Tu, L.; et al. Temperature response of soil carbon decomposition depends strongly on forest management practice and soil layer on the eastern Tibetan Plateau. Sci. Rep.-UK 2017, 7, 4777. [CrossRef]

20. Wang, J.; Song, C.; Zhang, J.; Wang, L.; Zhu, X.; Shi, F. Temperature sensitivity of soil carbon mineralization and nitrous oxide emission in different ecosystems along a mountain wetland-forest ecotone in the continuous permafrost of Northeast China. Catena 2014, 121, 110-118. [CrossRef]

21. Chen, Y.; Chen, G.; Robinson, D.; Yang, Z.; Guo, J.; Xie, J.; Fu, S.; Zhou, L.; Yang, Y. Large amounts of easily decomposable carbon stored in subtropical forest subsoil are associated with r-strategy-dominated soil microbes. Soil Biol. Biochem. 2016, 95, 233-242. [CrossRef]

22. Xiao, D.; Huang, Y.; Feng, S.; Ge, Y.; Zhang, W.; He, X.; Wang, K. Soil organic carbon mineralization with fresh organic substrate and inorganic carbon additions in a red soil is controlled by fungal diversity along a pH gradient. Geoderma 2018, 321, 79-89. [CrossRef]

23. Li, Z.; Zhang, T.; Chen, B. Dynamics of soluble organic carbon and its relation to mineralization of soil organic carbon. Acta Pedol. Sin. 2004, 41, 544-552. (In Chinese)

24. Chen, T.; Hao, X.; Du, L.; Lin, B.; Feng, M.; Hu, R.; Gao, J. Effects of long-term fertilization on paddy soil organic carbon mineralization. Chin. J. Appl. Ecol. 2008, 19, 1494-1500. (In Chinese)

25. Worrell, E.; Price, L.; Martin, N.; Hendriks, C.; Meida, L.O. Carbon dioxide emissions from the global cement industry. Annu. Rev. Energy Environ. 2001, 26, 303-329. [CrossRef]

26. Davidson, E.A.; Verchot, L.V.; Cattânio, J.H.; Ackerman, I.L.; Carvalho, J.E.M. Effects of soil water content on soil respiration in forests and cattle pastures of eastern Amazonia. Biogeochemistry 2000, 48, 53-69. [CrossRef]

27. Paustian, K.; Six, J.; Elliott, E.T.; Hunt, H.W. Management options for reducing CO2 emissions from agricultural soils. Biogeochemistry 2000, 48, 147-163. [CrossRef]

28. Yu, S.; Wang, J.; Gao, Y. Effect of plastic mulching and different fertilization treatments on soil microbial biomass carbon and nitrogen. J. Shenyang Agric. Univ. 2006, 37, 602-606. (In Chinese)

29. Ågren, G.I.; Bosatta, E.; Magill, A.H. Combining theory and experiment to understand effects of inorganic nitrogen on litter decomposition. Oecologia 2001, 128, 94-98. [CrossRef]

30. Ci, E.; Mahdi, A.-K.; Wang, L.; Ding, C.; Xie, D. Soil organic carbon mineralization as affected by cyclical temperature fluctuations in a karst region of southwestern China. Pedosphere 2015, 25, 512-523. [CrossRef]

31. Wang, H.; Fan, Z.; Deng, D. Effects of environmental factors on soil organic carbon mineralization in a pinus sylvestris var. mongolica plantation. Chin. J. Ecol. 2008, 27, 1469-1475. (In Chinese)

(C) 2019 by the authors. Licensee MDPI, Basel, Switzerland. This article is an open access article distributed under the terms and conditions of the Creative Commons Attribution (CC BY) license (http://creativecommons.org/licenses/by/4.0/). 